\title{
Anti-interferon- $\gamma$ Antibody-seropositive Disseminated Nontuberculous Mycobacterial Infection Mimicking POEMS and TAFRO Syndromes: A Case Report
}

\author{
Chiharu Hidekawa ${ }^{1}$, Ryusuke Yoshimi ${ }^{1}$, Daiga Kishimoto ${ }^{1}$, Hideaki Kato ${ }^{1,2}$, \\ Masaki Mitsuhashi ${ }^{1}$, Natsuki Sakurai ${ }^{1}$, Yuichiro Sato ${ }^{1}$, Takeaki Uehara ${ }^{3}$, Yuki Iizuka ${ }^{1}$, \\ Takaaki Komiya ${ }^{1}$, Naoki Hamada ${ }^{1}$, Hideto Nagai ${ }^{1}$, Yutaro Soejima ${ }^{1}$, Reikou Kamiyama ${ }^{1}$, \\ Kaoru Takase-Minegishi ${ }^{1}$, Yohei Kirino ${ }^{1}$, Takuro Sakagami ${ }^{4}$ and Hideaki Nakajima ${ }^{1}$
}

\begin{abstract}
:
Disseminated nontuberculous mycobacterial infection (DNTM) is typically observed in immunocompromised hosts. Recently, it has been reported that healthy individuals with serum neutralizing autoantibodies for interferon (IFN)- $\gamma$ can also develop DNTM. We herein report a case of anti-IFN- $\gamma$ antibody-seropositive DNTM caused by Mycobacterium kansasii with symptoms mimicking TAFRO or POEMS syndrome, including anasarca, organomegaly, skin pigmentation, polyneuropathy, osteosclerotic change, thrombocytopenia, serum $\mathrm{M}$ protein, high $\mathrm{C}$-reactive protein level, and reticulin fibrosis. The combination of antimicrobial chemotherapy with glucocorticoid and intravenous immunoglobulin improved his symptoms. Glucocorticoids may be an effective method of suppressing the production of anti-IFN- $\gamma$ antibodies in DNTM.
\end{abstract}

Key words: Disseminated nontuberculous mycobacterial infection, Anti-interferon- $\gamma$ antibody, Mycobacterium kansasii, TAFRO syndrome, POEMS syndrome

(Intern Med Advance Publication)

(DOI: 10.2169/internalmedicine.8366-21)

\section{Introduction}

Disseminated nontuberculous mycobacterial infection (DNTM) is observed in immunocompromised hosts, including patients with acquired immunodeficiency syndrome (AIDS), malignancies, diabetes mellitus, and congenital immunodeficiency diseases and those receiving immunosuppressive therapy. Because it is very rare for a healthy person to develop DNTM, this condition is not often considered as a differential diagnosis in patients without underlying diseases. Recently, however, it was reported that neutralizing autoantibodies for interferon (IFN)- $\gamma$ are commonly detected in the sera of DNTM patients who are otherwise healthy (1). TAFRO syndrome and POEMS syndrome are rare sys- temic diseases of unknown cause with elevated serum levels of vascular endothelial growth factor (VEGF) and interleukin (IL)-6 (2, 3). These two syndromes are often difficult to distinguish because they are accompanied by similar symptoms, including systemic edema, pleural effusion, ascites, renal damage, and lymphadenopathy with Castleman's disease-like histopathological findings (4). These symptoms can occur in a variety of diseases, including malignant tumors, collagen diseases, and infectious diseases. Immunosuppressive therapy, including glucocorticoids, is administered for these syndromes, and it is important to rule out the possibility of infectious diseases.

We herein report a case of a previously healthy patient with anti-IFN- $\gamma$ autoantibody-seropositive DNTM caused by Mycobacterium kansasii who presented with clinical features

\footnotetext{
${ }^{1}$ Department of Hematology and Clinical Immunology, Yokohama City University School of Medicine, Japan, ${ }^{2}$ Infection Prevention and Control Department, Yokohama City University Hospital, Japan, ${ }^{3}$ Department of Rheumatology, Chigasaki City Hospital, Japan and ${ }^{4}$ Department of Respiratory Medicine, Faculty of Life Sciences, Kumamoto University, Japan

Received: July 18, 2021; Accepted: November 25, 2021; Advance Publication by J-STAGE: January 13, 2022

Correspondence to Dr. Ryusuke Yoshimi, yoshiryu@med.yokohama-cu.ac.jp
} 
that mimicked TAFRO syndrome and POEMS syndrome and were improved by the combination of antimicrobial chemotherapy with glucocorticoids and intravenous immunoglobulin.

\section{Case Report}

A 64-year-old Japanese man was transferred to our hospital because of polyarthralgia and multiple cellulitis. Six months before hospitalization, he had visited a neighborhood hospital because of elevated hepatobiliary enzyme levels. Although he did not have any abdominal symptoms at that time, the serum levels of $\gamma$-GTP and alkaline phosphatase (ALP) were high $(217 \mathrm{U} / \mathrm{L}$ and 1,052 U/L, respectively). The serum C-reactive protein (CRP) level was also elevated to $12.32 \mathrm{mg} / \mathrm{dL}$. Computed tomography (CT) revealed consolidation in the inferior lobe of the left lung, hepatosplenomegaly, and multiple lymphadenopathies. Biopsies were performed in the cervical lymph nodes, liver, and lungs, but only nonspecific infiltration of inflammatory cells was observed. He was treated with $20 \mathrm{mg}$ prednisolone (PSL) for suspected systemic autoimmune disease. Four months later, he noticed swelling on the dorsal skin of the left hand and was treated with antibiotics for the diagnosis of cellulitis at another hospital. He was also suspected of having hepatobiliary disease because of the elevated hepatobiliary enzyme level, leukocytosis (white blood cell [WBC] count $24,000 / \mu \mathrm{L})$, and high serum CRP level $(16.55 \mathrm{mg} / \mathrm{dL})$, but there were no findings suggesting infection or tumor in his gallbladder. Although high serum levels of soluble IL-2 receptor $(13,400 \mathrm{U} / \mathrm{mL})$ and multiple lymphadenopathies were observed, there were no findings of malignancy in the cervical lymph node biopsy.

On admission to our department, physical examination revealed significant tabescence, skin pigmentation, and edema of the lower extremities. He also had swelling of the axillary lymph nodes and knee joint pain. He had no abdominal symptoms or numbness. His blood pressure was 112/66 $\mathrm{mmHg}$, pulse was $98 / \mathrm{min}$, temperature was $36.4{ }^{\circ} \mathrm{C}$, and $\mathrm{O}_{2}$ saturation was $96 \%$ on ambient air.

Laboratory data revealed increased levels of serum CRP, erythrocyte sedimentation rate, WBCs (especially neutrophils), and elevated ALP and soluble IL-2 receptor levels (Table 1). He had anemia, but his mean corpuscular volume and haptoglobin levels were within the respective normal ranges. Total protein and albumin levels were low, his renal function was normal, and the brain natriuretic peptide level was slightly increased. Serum M protein ( $\operatorname{IgG}-\lambda$ type Bence Jones protein) was also detected. We also examined the possibility of infectious diseases, including hepatitis B, hepatitis C, Epstein-Barr virus, HIV, human T-cell leukemia virus type 1 , and tuberculosis, but all were negative.

Chest radiography showed a reticular shadow on both lower lungs and the right costophrenic angle was slightly dull. Electrocardiography findings were normal. Chest and abdominal CT revealed pleural effusion and ascites; hepa- tosplenomegaly; paraaortic and pelvic lymphadenopathy; and osteosclerotic and osteolytic changes in the spine, ribs, and pelvis (Fig. 1a, b, and c). A bone marrow biopsy showed an increase in reticulum fibers, appearance of collagen fibers, myeloid-rich hypercellular mallow with a variety of cells, and no monoclonal proliferation of plasma cells. The number and size of the bone marrow megakaryocytes did not increase remarkably. The bone marrow biopsy did not reveal any acid-fast bacilli and did not show any granulomatous formations. Because he also had hypesthesia in his lower extremities, we performed a nerve conduction velocity study, which revealed polyneuropathy.

Based on these findings, we suspected TAFRO syndrome due to anasarca (pleural effusion, ascites, and edema), thrombocytopenia, high CRP levels, reticulin fibrosis in the bone marrow, and organomegaly (hepatosplenomegaly and lymphadenopathy). However, findings of $\mathrm{M}$ protein, skin and bone lesions, and polyneuropathy are not consistent with TAFRO syndrome. A lymph node biopsy from the cervical region indicated lymphocyte infiltration and fibrosis in the lymph nodes, but there were no Castleman disease-like findings. Another differential diagnosis was POEMS syndrome due to his polyneuropathy, serum M protein (IgG- $\lambda$ type), osteosclerotic changes, organomegaly, fluid retention, and skin pigmentation. However, the serum VEGF levels were not markedly elevated $(823 \mathrm{pg} / \mathrm{mL})$, and there were no endocrine abnormalities. The osteolytic changes were also not consistent with POEMS syndrome. Given that the use of glucocorticoids might modify the condition, we tapered the PSL dose (Fig. 2).

On day 36, subcutaneous masses appeared on his left hand and thigh, and ulcers appeared on the left elbow, right finger, and middle toe. Skin biopsies revealed that the masses were due to subcutaneous abscess formation. ZiehlNeelsen staining of the abscess revealed acid-fast bacilli. We also performed Ziehl-Neelsen staining of sputum and bile smears, and both samples were positive. Polymerase chain reaction of the sputum was negative for Mycobacterium tuberculosis, M. avium, and M. intracellulare. Due to suspected nontuberculous mycobacterial infection, we further tapered the PSL dose to $5 \mathrm{mg} /$ day. Since the identification of the bacterial species was necessary for the selection of the treatment regimen, he was temporarily transferred to the previous hospital for rehabilitation on day 53 until the bacterial species were identified by the various cultures submitted.

Ultimately, M. kansasii was identified from cultures of both gastric juice and subcutaneous abscesses using the DNA-DNA hybridization method. Susceptibility testing using the broth microdilution method (BrothMIC NTM; Kyokuto, Tokyo, Japan) revealed that the minimum inhibitory concentrations for the drugs were as follows: rifampicin, $0.125 \mu \mathrm{g} / \mathrm{mL}$; levofroxacin, $0.25 \mu \mathrm{g} / \mathrm{mL}$; clarithromycin, $0.125 \mu \mathrm{g} / \mathrm{mL}$; and ethambutol, $1 \mu \mathrm{g} / \mathrm{mL}$.

We diagnosed the patient with DNTM caused by M. kansasii. On day 140, the patient was transferred to our hospital 
Table 1. Laboratory Data on Admission.

\begin{tabular}{|c|c|c|}
\hline Variable & Reference range & On admission \\
\hline Erythrocyte count $\left(\times 10^{4} / \mathrm{mm}^{3}\right)$ & $414-534$ & 307 \\
\hline Hemoglobin $(\mathrm{g} / \mathrm{dL})$ & $13.8-17.2$ & 9.2 \\
\hline Mean corpuscular volume (fL) & $83-100$ & 92.4 \\
\hline White-blood cell count $\left(/ \mathrm{mm}^{3}\right)$ & $3,300-9,400$ & 20,800 \\
\hline \multicolumn{3}{|l|}{ White-blood cell differential count (\%) } \\
\hline Neutrophils & $37.5-66.0$ & 88.5 \\
\hline Lymphocytes & $19.5-47.0$ & 4.5 \\
\hline Monocytes & $2.2-10.4$ & 6.0 \\
\hline Eosinophils & $0-6.0$ & 0.0 \\
\hline Basophils & $0-1.8$ & 0.0 \\
\hline Platelet count $\left(\times 10^{4} / \mathrm{mm}^{3}\right)$ & $18.0-39.0$ & 15.8 \\
\hline Erythrocyte sedimentation rate $(\mathrm{mm} / \mathrm{h})$ & $2-10$ & 74 \\
\hline PT (INR) & $0.87-1.15$ & 1.21 \\
\hline Activated partial thromboplastin time (s) & $25.0-35.0$ & 27 \\
\hline Fibrinogen (mg/dL) & $186-385$ & 444 \\
\hline FDP D-dimer $(\mu \mathrm{g} / \mathrm{mL})$ & $0.0-0.7$ & 5.27 \\
\hline Creatinine $(\mathrm{mg} / \mathrm{dL})$ & $0.68-1.04$ & 0.56 \\
\hline Urea nitrogen $(\mathrm{mg} / \mathrm{dL})$ & $8-20$ & 14 \\
\hline Creatine kinase (U/L) & $64-255$ & 6 \\
\hline Aspartate aminotransferase (U/L) & $14-32$ & 10 \\
\hline Alanine aminotransferase (U/L) & $11-45$ & 8 \\
\hline$\gamma$-glutamyl transpeptidase (U/L) & $10-58$ & 129 \\
\hline Alkaline phosphatase (U/L) & $112-334$ & 875 \\
\hline Lactate dehydrogenase (IU/L) & $125-225$ & 101 \\
\hline Total bilirubin $(\mathrm{mg} / \mathrm{dL})$ & $0.4-1.5$ & 1.5 \\
\hline Sodium $(\mathrm{mEq} / \mathrm{L})$ & $138-144$ & 140 \\
\hline Potassium $(\mathrm{mEq} / \mathrm{L})$ & $3.7-5.0$ & 3.3 \\
\hline Chloride $(\mathrm{mEq} / \mathrm{L})$ & $100-108$ & 101 \\
\hline C-reactive protein $(\mathrm{mg} / \mathrm{dL})$ & $0.0-0.20$ & 8.77 \\
\hline Total protein $(\mathrm{g} / \mathrm{dL})$ & 6.1 & $6.9-8.3$ \\
\hline Albumin $(\mathrm{g} / \mathrm{dL})$ & $4.1-5.1$ & 2.3 \\
\hline $\mathrm{HbAlc}(\%)$ & $4.6-6.2$ & 4.6 \\
\hline Serum ferritin $(\mathrm{ng} / \mathrm{mL})$ & $25-280$ & 302 \\
\hline Procalcitonin (ng/mL) & $0.0-0.05$ & 0.57 \\
\hline Soluble interleukin-2 receptor $(\mathrm{U} / \mathrm{mL})$ & $145-519$ & 5369 \\
\hline $\mathrm{ACE}(\mathrm{U} / \mathrm{L})$ & $7.0-25$ & 7.7 \\
\hline $\mathrm{BNP}(\mathrm{pg} / \mathrm{mL})$ & $0.0-18.4$ & 110.8 \\
\hline Haptoglobin (mg/dL) & $19-170$ & 174 \\
\hline $\operatorname{IgG}(\mathrm{mg} / \mathrm{dL})$ & $870-1,700$ & 1,666 \\
\hline $\operatorname{IgA}(\mathrm{mg} / \mathrm{dL})$ & $110-410$ & 319 \\
\hline $\operatorname{IgM}(\mathrm{mg} / \mathrm{dL})$ & $33-190$ & 113 \\
\hline $\mathrm{IgG} 4(\mathrm{mg} / \mathrm{dL})$ & $4.5-117$ & $<2.0$ \\
\hline $\mathrm{C} 3(\mathrm{mg} / \mathrm{dL})$ & $70-129$ & 153 \\
\hline $\mathrm{C} 4(\mathrm{mg} / \mathrm{dL})$ & $12-36$ & 25 \\
\hline Antinuclear antibody (n times) & $0-40$ & $<40$ \\
\hline Rheumatoid factor (IU/mL) & $0.0-15$ & 329.8 \\
\hline MPO-ANCA (U/mL) & $0-3.5$ & $<1.0$ \\
\hline PR3-ANCA (U/mL) & $0-3.5$ & $<1.0$ \\
\hline ASO (IU/mL) & $0.0-239$ & 57 \\
\hline HTLV-I/II antibody & negative & negative \\
\hline$\beta$-D glucan $(\mathrm{pg} / \mathrm{mL})$ & $0.0-11$ & $<6.0$ \\
\hline T-SPOT & negative & negative \\
\hline Nil (negative control) & $\leq 10$ & 0 \\
\hline ESAT-6 & $\leq 5$ & 0 \\
\hline CFP10 & $\leq 5$ & 0 \\
\hline Mitogen (positive control) & $\geq 20$ & 588 \\
\hline HIV antigen antibody testing & negative & negative \\
\hline \multicolumn{3}{|l|}{ Urinalysis } \\
\hline Uric protein & $(-)$ & $(1+)$ \\
\hline Uric blood & $(-)$ & $( \pm)$ \\
\hline \multicolumn{3}{|l|}{ Urinary sediment } \\
\hline Red cells (/HPF) & $0-4$ & $1-4$ \\
\hline White cells (/HPF) & $0-4$ & $\geq 50$ \\
\hline Albumin creatinine ratio $(\mathrm{g} / \mathrm{gCr})$ & & 0.20 \\
\hline \multicolumn{3}{|l|}{ Non-acid-fast bacteria culture } \\
\hline Blood & negative & negative \\
\hline Urine & negative & negative \\
\hline Sputum & negative & negative \\
\hline Subcutaneous abscess & negative & negative \\
\hline \multicolumn{3}{|l|}{ Acid-fast bacteria culture } \\
\hline Blood & negative & negative \\
\hline Gastric juice & negative & Mycobacterium kansasii \\
\hline Subcutaneous abscess & negative & Mycobacterium kansasii \\
\hline
\end{tabular}

PT: prothrombin time, INR: international normalized ratio, FDP: fibrin degradation products, HbA1c: hemoglobin A1c, ACE: angiotensin-converting enzyme, BNP: brain natriuretic peptide, Ig: immunoglobulin, MPO: myeloperoxidase, ANCA: antineutrophil cytoplasmic antibodies, ASO: antistreptolysin O, HTLV: human T-cell leukemia-lymphoma virus, HPF: high-power field 

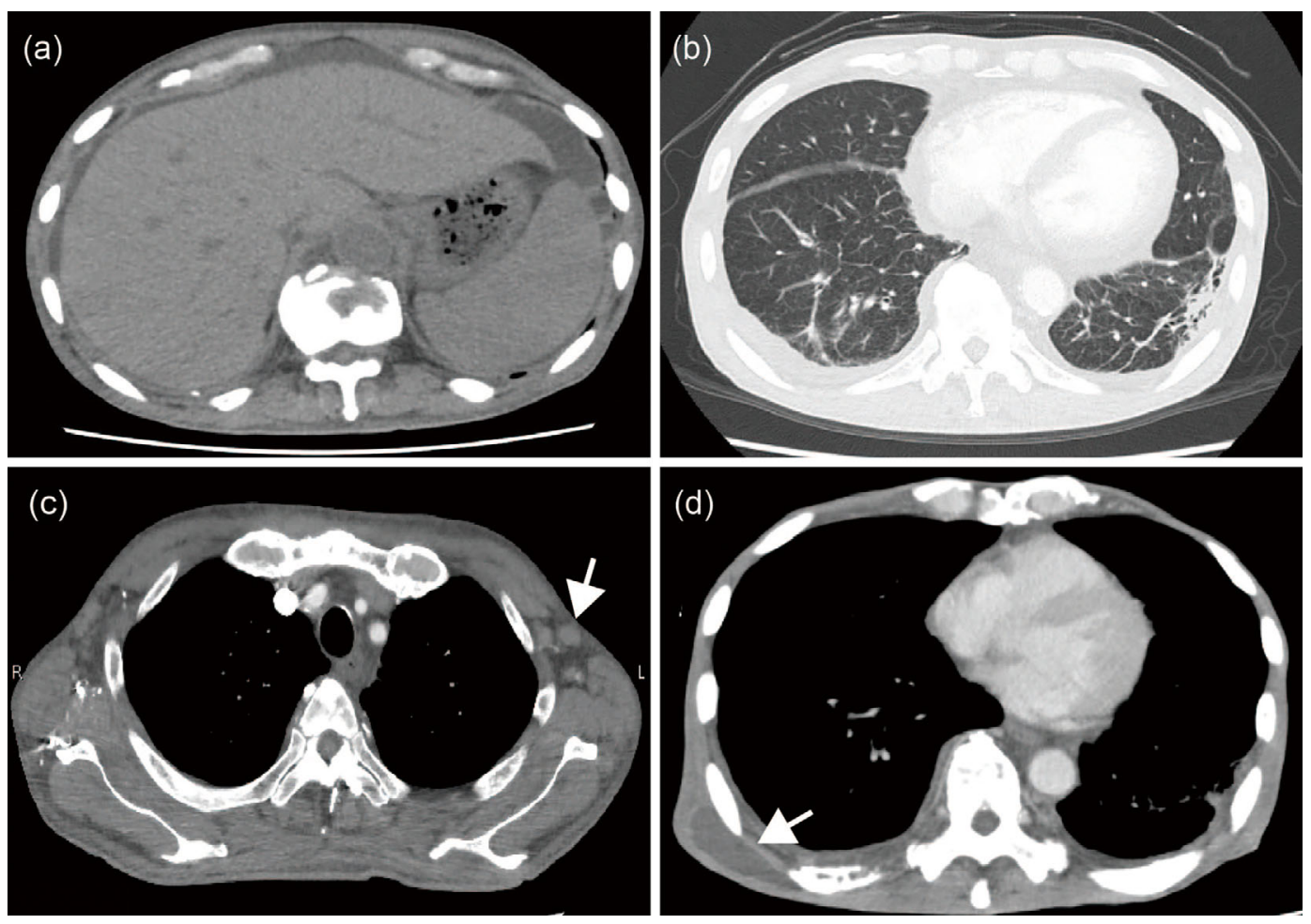

Figure 1. Axial contrast-enhanced computed tomography images. Hepatosplenomegaly and ascites (a) were observed on computed tomography (CT) three days before transfer to our hospital. Contrast-enhanced CT revealed consolidation in the lower lobe of the left lung (b) and multiple lymphadenopathies (c; arrow) at day 7 in our hospital. Many subcutaneous abscesses were observed in the CT images at approximately day 140 (d; arrow).

and treated with rifampicin (450 mg/day orally [p.o.]), clarithromycin (800 mg/day p.o.), and ethambutol $(750 \mathrm{mg} /$ day p.o.) (Fig. 2). He had scattered subcutaneous masses and osteolytic changes (Fig. 3,4). Since his general condition temporarily worsened afterwards, we changed the treatment regimen to rifampicin combined with isoniazid (300 mg/day p.o.) and ethambutol.

In parallel, we investigated whether or not the patient had an immunodeficiency source that would cause DNTM. The serum IFN- $\gamma$ concentration was measured by an enzyme immunoassay and found to be below the detection limit $(\leq 0.1$ $\mathrm{IU} / \mathrm{mL}$ ). Because the positive control antigen generated many IFN- $\gamma$-producing $\mathrm{T}$ cells, we suspected the existence of a neutralizing antibody for IFN- $\gamma$ in his sera. An enzymelinked immunosorbent assay revealed elevated anti-IFN- $\gamma$ antibody serum levels (308.7 E.U.; 5-50 for healthy control), and the phosphorylation index of signal transducer and activator of transcription 1 (STAT1), an IFN- $\gamma$ signaling downstream transcription factor, was suppressed $(44.77 ;>200$ for healthy controls). These results suggest that the presence of serum anti-IFN- $\gamma$ neutralizing antibodies can exacerbate DNTM.

On day 163, he showed impaired consciousness and hypoglycemia, and adrenal insufficiency was suspected. After we administered $200 \mathrm{mg} /$ day of intravenous hydrocortisone for 3 days, his condition improved. Following this, we increased the oral PSL dose to $20 \mathrm{mg} /$ day in addition to ad- ministering antibacterial chemotherapy to suppress anti-IFN$\gamma$ autoantibody production (Fig. 2). We also added intravenous immunoglobulin ( $5 \mathrm{~g} /$ day) for the treatment of DNTM on days 160-162. His disease condition, including arthralgia and subcutaneous abscess, gradually improved. Blood tests also revealed a gradual improvement in the serum levels of CRP and liver enzymes. The serum IFN- $\gamma$ level became detectable $(0.2 \mathrm{IU} / \mathrm{mL})$ on day 210 , and the anti-IFN- $\gamma$ antibody level showed a decreasing trend (190.53 E.U.). On day 260 , the patient was discharged with a successfully tapered PSL dose $(9 \mathrm{mg} /$ day). Antibiotic therapy, including isoniazid, rifampicin, and ethambutol, was continued for 2 years, and the PSL dose was further tapered to $5 \mathrm{mg} /$ day. There was no apparent sign of infection resurgence after two years of antibiotic therapy.

\section{Discussion}

Nontuberculous mycobacteria are widely present in the environment, such as in the soil and water. Aerosols from the environment cause transrespiratory tract infections as immunity weakens. Nontuberculous mycobacteria typically produce local lesions mainly in the bronchi and lungs. In rare cases, nontuberculous mycobacteria can be hematogenously disseminated and form lesions in multiple organs, such as DNTM.

DNTM is typically observed in patients with immunodefi- 


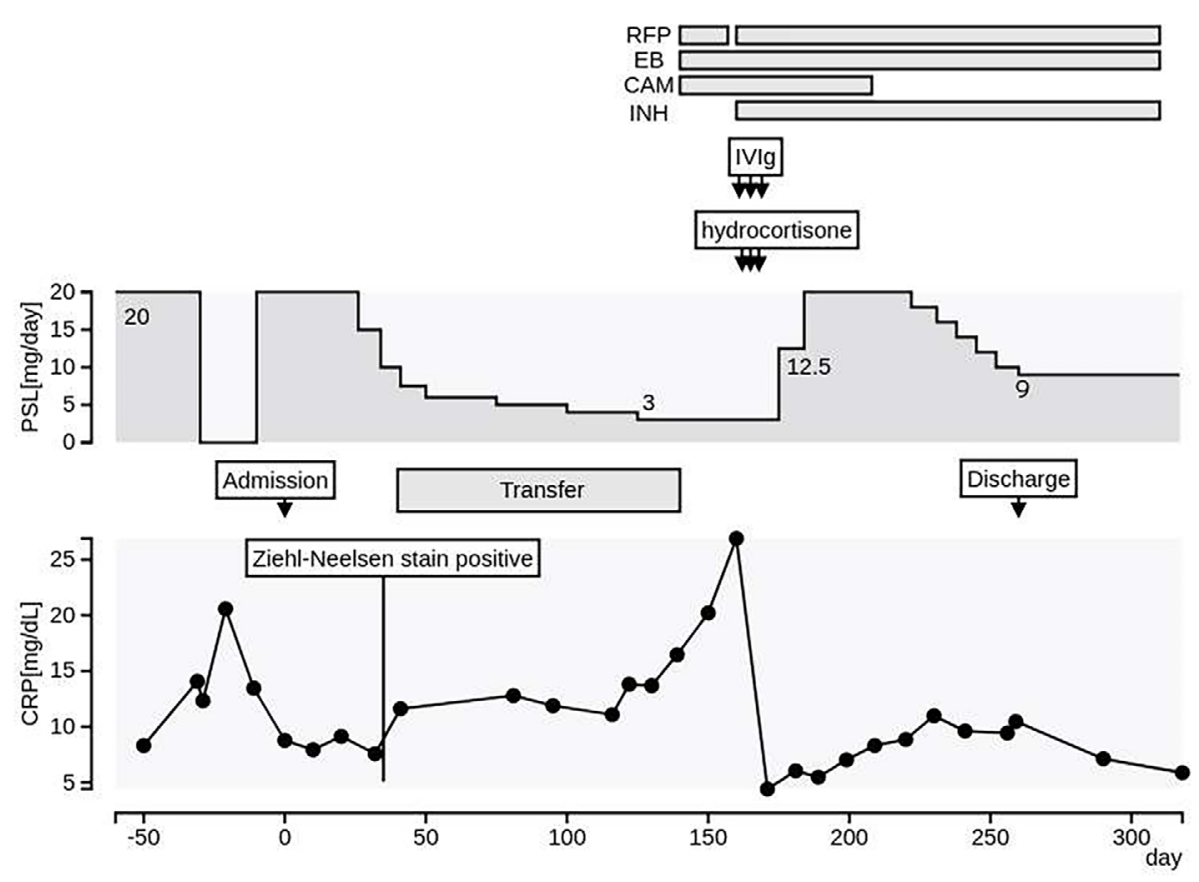

Figure 2. The patient's clinical course. After he was transferred to our hospital, the prednisolone (PSL) dose was gradually tapered. He was temporarily transferred to the previous hospital until the NTM species were identified (days 53-139). With the identification of $M$. kansasii, we re-transferred him to our hospital and started treatment with rifampicin (RFP), clarithromycin (CAM), and ethambutol (EB) on day 140. Since his general condition temporarily worsened, we added isoniazid (INH) to the treatment regimen. From day 163, we administered $200 \mathrm{mg} / \mathrm{day}$ of intravenous hydrocortisone for 3 days because of suspected adrenal insufficiency, followed by an increase in the oral PSL dose to $20 \mathrm{mg} /$ day to suppress anti-interferon (IFN) $-\gamma$ autoantibody production. We also added intravenous immunoglobulin for the treatment of disseminated nontuberculous mycobacterial infection (DNTM) on days 160-162. On day 260, the patient was discharged with a successfully tapered PSL dose.
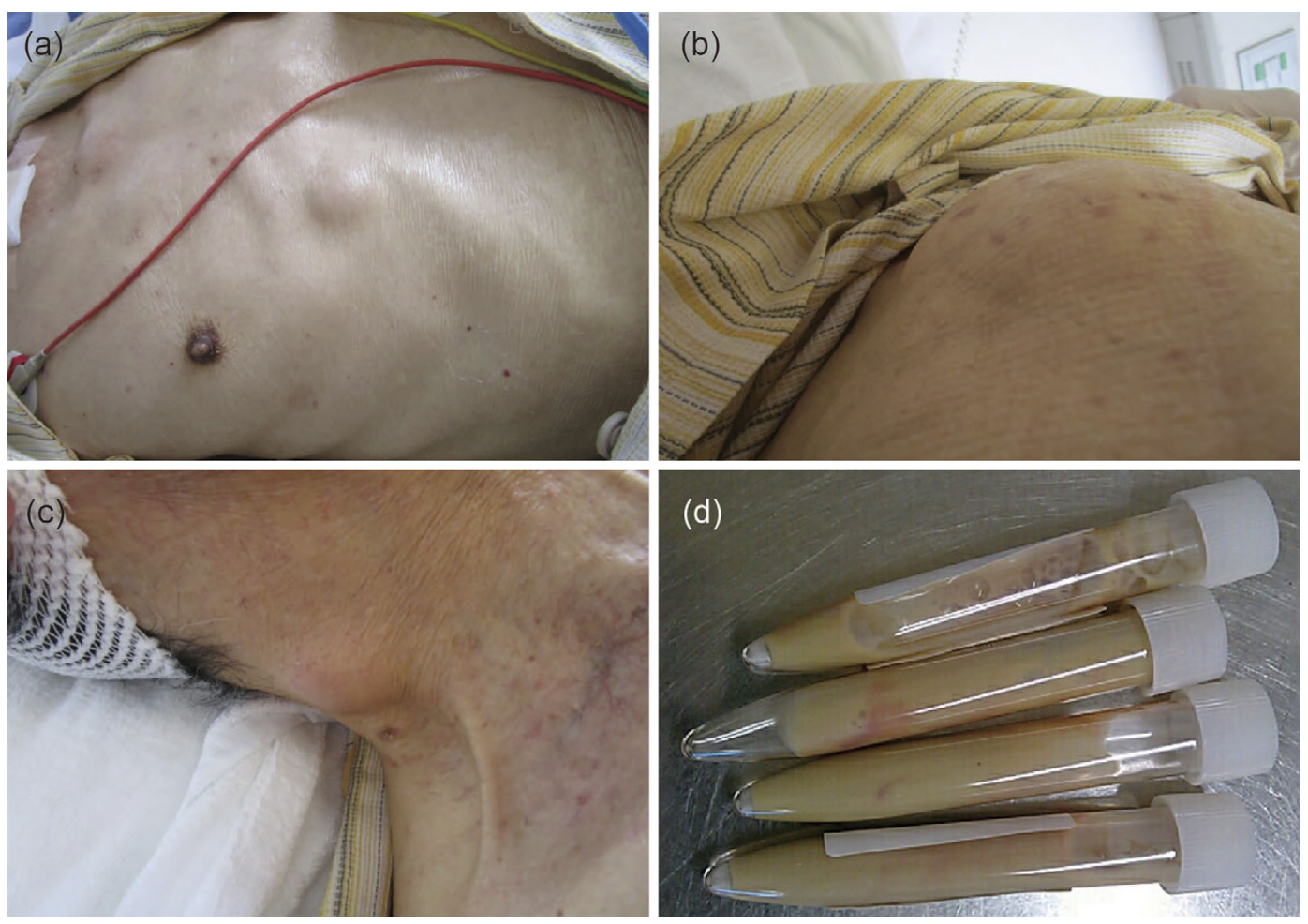

Figure 3. Multiple subcutaneous abscesses. Many subcutaneous masses were observed on the right anterior chest (a), right back (b), and right neck (c) at approximately day 140. Puncture of the subcutaneous mass on the right back revealed the presence of purulent fluid (d). 


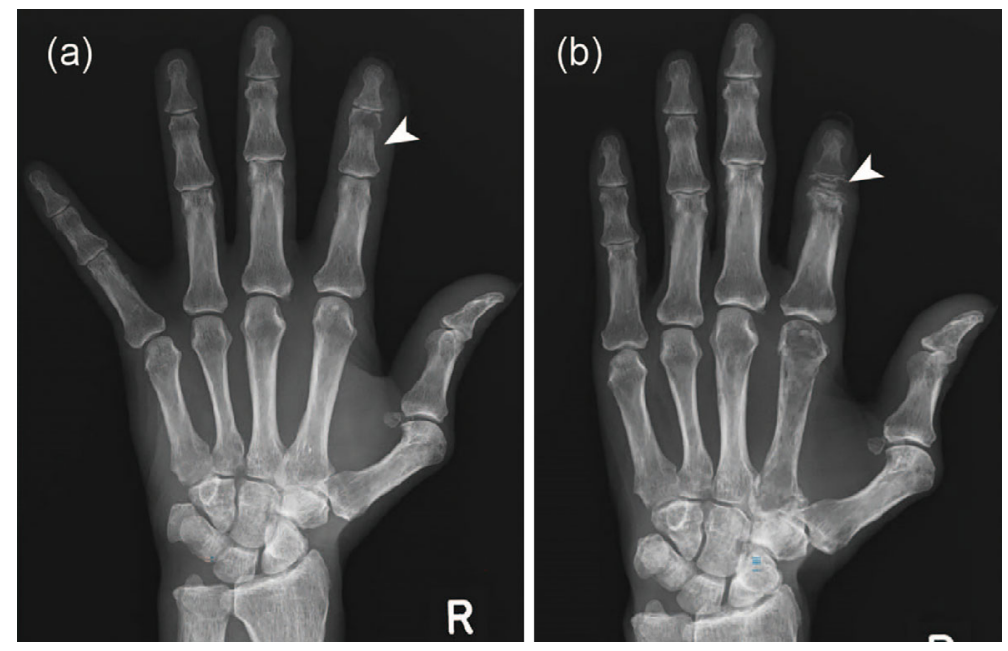

Figure 4. Osteolytic changes in the second middle phalanx of the right hand. On comparing hand $X$-ray images obtained on days 26 (a) and 182 (b), a diffuse reduction in bone density was noted. Osteolytic changes were observed in the second middle phalanx of the right hand, and the second finger was shortened (arrow).

ciency, such as AIDS, hematological malignancies, and congenital immunodeficiency diseases, and those using immunosuppressants (5). In this case, the patient had no underlying disease and no history of immunosuppressive drug use. It has been reported that anti-IFN- $\gamma$ neutralizing autoantibodies are often found in DNTM without underlying diseases (6). In recent years, an increasing number of case reports regarding anti-IFN- $\gamma$ antibody-positive DNTM have been published. Table 2 shows cases of anti-IFN- $\gamma$ antibodypositive DNTM reported from Japan. As in the present case, most of them have clinical characteristics of disseminated lesions, mainly in the bone and soft tissues.

IFN- $\gamma$ is an important cytokine in the host defense system against mycobacteria, and IFN- $\gamma$ deficiency increases the risk of mycobacteriosis. Regarding laboratory tests suggesting the presence of anti-IFN- $\gamma$ antibody, a discrepancy has been reported between the results of T SPOT-TB (T-SPOT) and QuantiFERON TB-3 G (QFT-3 G), both of which are IFN- $\gamma$ release assays (IGRA) (7). Since whole blood is used in QFT-3 G, the positive control becomes less sensitive in the presence of neutralizing antibodies; in addition, there is a discrepancy with regard to the results of T-SPOT using purified lymphocytes. It is possible that there was a discrepancy between the results of QFT-3 G and T-SPOT in this case as well, but we did not measure QFT-3 G because this evaluation is not performed daily at our hospital. As serum anti-IFN- $\gamma$ neutralizing antibodies were detected in this case, we concluded that deficiency in IFN- $\gamma$-dependent cellmediated immunity was the main cause of DNTM. Attenuation of the action of IFN- $\gamma$ by the anti-IFN- $\gamma$ antibodies also reduces the production of IL-12, which further reduces the production of IFN- $\gamma$. Therefore, it is quite possible that the serum IL-12 levels were low in this case. In fact, severe NTM cases with mutations in genes involved in the IL-12/ IFN- $\gamma$ pathway, such as $I L-12 B, I L-12 R B 1$, IFNGR1, STAT1, and $I R F 8$, have been reported (8). In this case, we did not search for abnormalities in these genes, as anti-IFN- $\gamma$ antibodies were detected and there was no notable history of infectious diseases until later in life.

No consensus concerning the optimal treatment strategy for DNTM with anti-IFN- $\gamma$ antibodies has yet been reached. While some patients respond to conventional multidrug antibacterial chemotherapy, others are resistant. Treatment strategies that suppress autoantibody production have been attempted in intractable cases. There are some reports that immunoglobulin therapy, plasma exchange with cyclophosphamide, and rituximab, which target the reduction of antibody production by $\mathrm{B}$ cell suppression, were effective (9-11). In this case, PSL was started because the previous clinician suspected systemic autoimmune disease. In the process, IFN- $\gamma$ was measured multiple times, and positive conversion of IFN- $\gamma$ was observed after the oral PSL dose was increased to $20 \mathrm{mg} /$ day, remaining positive even after glucocorticoid reduction. Whether or not this was related to disease activity is unclear, but the titer of anti-IFN- $\gamma$ neutralizing antibody decreased after increasing the glucocorticoid dose. We tapered glucocorticoids due to the risks of complications, including other opportunistic infections and osteoporosis progression, although we considered that it might suppress the production of anti-IFN- $\gamma$ neutralizing antibodies. Thus far, there have been no reports concerning the efficacy of glucocorticoids for anti-IFN- $\gamma$ neutralizing antibodypositive DNTM, and the further accumulation and analyses of such cases are expected in future studies.

In this case, M. kansasii was detected in the gastric juice and subcutaneous tissue. M. kansasii accounts for approximately $4 \%$ of nontuberculous mycobacterial disease cases in Japan (12). Many of the patients affected by M. kansasii are middle-aged, and some background diseases, such as chronic obstructive lung disease and malignancy, are reported as risk factors (13). Aoki et al. reported that there were many cases of seropositivity for anti-IFN- $\gamma$ neutralizing 
Table 2. Case Reports of DNTM Seropositive for Anti-IFN- $\gamma$ Antibodies from Japan.

\begin{tabular}{|c|c|c|c|c|c|c|c|}
\hline Case & $\begin{array}{l}\text { Age } \\
\text { (years)/ } \\
\text { Sex }\end{array}$ & Underlying condition & Strain & Symptom/Findings & Treatment & Outcome & Reference \\
\hline 1 & $53 / \mathrm{M}$ & Unknown & M.kansasii & $\begin{array}{l}\text { Dyspnea, Anemia, Mediastinal } \\
\text { lymphadenopathy }\end{array}$ & RFP/EB/INH & Died & (22) \\
\hline 2 & $66 / M$ & Hepatitis C & M. aviumcomplex & $\begin{array}{l}\text { Fever, Back pain, Joint pain, } \\
\text { Myalgia, Lung lesion, } \\
\text { Mediastinal lymphadenopathy }\end{array}$ & $\begin{array}{l}\mathrm{RFP} / \mathrm{EB} / \mathrm{CAM} / \\
\mathrm{LVFX}+\text { drainage }\end{array}$ & Improved & (23) \\
\hline 3 & $74 / \mathrm{W}$ & None & M. fortuitum & $\begin{array}{l}\text { Fever, Cough, Lung lesion, } \\
\text { Cervical lymphadenopathy }\end{array}$ & $\begin{array}{l}\mathrm{IPM} / \mathrm{CS}+\mathrm{AMK} \rightarrow \\
\mathrm{LVFX} / \mathrm{CAM}\end{array}$ & Improved & (24) \\
\hline 4 & $65 / M$ & Unknown & $\begin{array}{l}\text { M. gordonael } \\
\text { M. manteni }\end{array}$ & $\begin{array}{l}\text { Fever, Weight loss, Cervical } \\
\text { lymphadenopathy, Lung } \\
\text { lesion, Bone lesion }\end{array}$ & RFP/EB/CAM & Improved & (25) \\
\hline 5 & $67 / \mathrm{W}$ & Diabetes mellitus & M. aviumcomplex & $\begin{array}{l}\text { Fever, Weight loss, Lumbago, } \\
\text { Hepatosplenomegaly, Edema, } \\
\text { Osteolytic lesion }\end{array}$ & $\begin{array}{l}\text { RFP/EB/CAM/ } \\
\text { STFX+RTX }\end{array}$ & Improved & (26) \\
\hline 6 & 79/W & None & M. phlei & $\begin{array}{l}\text { Chest pain, Erythema, } \\
\text { Multiple lymphadenopathy, } \\
\text { Osteolytic lesion, } \\
\text { Hepatosplenomegaly }\end{array}$ & $\begin{array}{l}\text { RFP/EB/CAM/ } \\
\text { LVFX }\end{array}$ & Improved & (27) \\
\hline 7 & $74 / \mathrm{W}$ & Unknown & M. avium & Lymphadenopathy,Abscess & RFP/EB/CAM & Improved & $(28)$ \\
\hline 8 & $33 / \mathrm{M}$ & None & M. kansasii & $\begin{array}{l}\text { Fever, Cough, Multiple } \\
\text { lymphadenopathy, Pericardial } \\
\text { effusion, Pleural effusion }\end{array}$ & RFP/EB/INH/PZA & Improved & (29) \\
\hline 9 & $68 / \mathrm{M}$ & None & M. avium & $\begin{array}{c}\text { Fever, Weight loss, Lung } \\
\text { lesion, Osteolytic lesion, } \\
\text { Hepatosplenomegaly, Ascites, } \\
\text { Intraperitoneal } \\
\text { lymphadenopathy }\end{array}$ & $\begin{array}{l}\mathrm{RFP} / \mathrm{EB} / \mathrm{CAM} / \mathrm{SM} \\
\rightarrow \text { add STFX }\end{array}$ & Improved & (30) \\
\hline 10 & $65 / M$ & None & M. avium & $\begin{array}{l}\text { Erythema, Weight loss, } \\
\text { Numbness, Multiple } \\
\text { lymphadenopathy, Osteolytic } \\
\text { lesion, Abscess }\end{array}$ & $\begin{array}{l}\mathrm{RFP} / \mathrm{EB} / \mathrm{CAM} \rightarrow \\
\mathrm{CAM} / \mathrm{RBT} / \mathrm{EB} / \mathrm{SM} \\
+ \text { IFN- } \gamma \text { s.c. }\end{array}$ & Improved & (31) \\
\hline 11 & $78 / \mathrm{M}$ & $\begin{array}{l}\text { Cervical spondylosis } \\
\text { Hypertension }\end{array}$ & M. abium & $\begin{array}{c}\text { Fever, Weight loss, Multiple } \\
\text { lymphadenopathy, Lung } \\
\text { lesion, Osteolytic lesion, } \\
\text { Pleural effusion }\end{array}$ & RFP/EB/CAM/SM & Improved & (32) \\
\hline 12 & $49 / \mathrm{W}$ & None & M. abscessus & $\begin{array}{c}\text { Fever, Multiple } \\
\text { lymphadenopathy, Bone lesion }\end{array}$ & $\begin{array}{l}\text { MEPM/AMK/ } \\
\text { CAM }\end{array}$ & Improved & (33) \\
\hline 13 & $72 / \mathrm{M}$ & $\begin{array}{c}\text { Hypertension } \\
\text { Hyperuricemia Ossification } \\
\text { of cervical posterior } \\
\text { longitudinal ligament }\end{array}$ & M. abium & $\begin{array}{l}\text { Fever, Abdominal pain, Renal } \\
\text { swelling, Osteolytic lesion, } \\
\text { Lung lesion }\end{array}$ & $\begin{array}{l}\text { RFP/CAM + } \\
\text { Glucocorticoid }\end{array}$ & Died & (34) \\
\hline 14 & $64 / M$ & None & M. kansasii & $\begin{array}{l}\text { Fever, Polyarthralgia, Multiple } \\
\text { cellulitis, Pleural effusion, } \\
\text { Ascites, Hepatosplenomegaly, } \\
\text { Multiple lymphadenopathy, } \\
\text { Osteolytic lesion }\end{array}$ & $\begin{array}{c}\text { RFP/EB/CAM } \rightarrow \\
\text { RFP/EB/CAM/INH } \\
+ \text { Glucocorticoid/ } \\
\text { IVIg }\end{array}$ & Improved & - \\
\hline
\end{tabular}

Case 14 is our case.

RFP: rifampicin, EB: ethambutol, INH: isoniazid, CAM: clarithromycin, LVFX: levofloxacin, IPM/CS: imipenem/cilastatin, AMK: amikacin, STFX: sitafloxacin, RTX: rituximab, PZA: pyrazinamide, SM: streptomycin, RBT: rifabutin, IFN- $\gamma$ s.c.: interferon-gamma subcutaneous injection, MEPM: meropenem, M: man, W: woman

antibodies in DNTM in Japan, the majority of which were caused by $M$. avium complex $(70.3 \%)$, and only 1 of 31 cases was caused by M. kansasii (2.7\%) (14). While skin lesions caused by $M$. kansasii are prone to manifest as raised lesions and ulcers in immune-responsive patients, there are reports of diffuse cellulitis and seroma in immunocompromised patients $(15,16)$. In the current case, the skin lesions showed cellulitis and abscesses with a highly viscous milky white fluid, similar to those of immunocompromised patients with DNTM. The standard treatment regimen for $M$. kansasii DNTM is the same as that for M. kansasii pulmonary infection, which includes isoniazid (300 mg/day), rifampicin (600 mg/day), and ethambutol (15 mg/kg/day), according to the official statement of the American Thoracic Society and Infectious Diseases Society of America (13). However, several reports have shown the effectiveness of treatment with rifampicin, ethambutol, and clarithromycin for M. kansasii infection $(17,18)$. Although we started treat- 
ment with these three drugs, we changed the regimen to rifampicin, ethambutol, and isoniazid as recommended by the American Thoracic Society and Infectious Diseases Society of America as the patient's general condition worsened. It is recommended that the duration of treatment of DNTM with M. kansasii be the same as that of DNTM with M. avium complex and that lifelong treatment be considered in DNTM with $M$. avium complex unless immune recovery is achieved. Even in the current case, in which the symptoms and laboratory findings improved considerably during hospitalization, treatment for DNTM will be continued for an extended period in the outpatient clinic.

This case initially showed liver damage and an increased inflammatory response and subsequently developed systemic symptoms including pulmonary lesions, lymphadenopathy, skin lesions, hepatosplenomegaly, and joint pain. Based on these findings, we suspected POEMS syndrome or TAFRO syndrome. The symptoms, such as fever, thrombocytopenia, pleural and ascitic fluid retention, and reticulin fibrosis of the bone marrow, met the Ministry of Health, Labor and Welfare, Japan diagnostic criteria for TAFRO syndrome (19). In general, however, hepatosplenomegaly and lymphadenopathy are often mild, and $\mathrm{M}$ protein is not observed in TAFRO syndrome. Progressive renal dysfunction, which is described as a minor criterion, was not observed in this case. Furthermore, we noted no pathological lymph node findings suggestive of TAFRO syndrome similar to the mixed type (mixture of vitreous vascular type and plasma cell type) of multicentric Castleman's disease in this case $(3,19,20)$. One case report has described a DNTM case in which manifestations confusingly met the diagnostic criteria of TAFRO syndrome (21). In that case, the causative organism was $M$. genavence. The manifestations were similar to those in our case, including multiple lymphadenopathies, thrombocytopenia, hepatosplenomegaly, fluid retention, and fibrosis of the bone marrow. Although the authors did not measure the serum anti-IFN- $\gamma$ antibodies, they suspected the presence of anti-IFN- $\gamma$ antibodies because the positive control of QuantiFERON TB was negative. In common with our case, a high serum level of ALP, which is one of the important findings of DNTM (13), was also observed. In our case, the serum ALP level showed a persistently high level from the patient's first visit to the previous hospital. It is highly possible that DNTM was the main cause of the elevation of the ALP level. Because elevated serum ALP levels are seen in TAFRO syndrome, DNTM is important as a differential diagnosis when TAFRO syndrome is suspected. Indeed, the Ministry of Health, Labor and Welfare diagnostic criteria for TAFRO syndrome include mycobacteriosis as a differential diagnosis (19). POEMS syndrome was also suspected based on the $\mathrm{M}$ protein and multiple neuropathies in this case. Castleman's disease-like findings were observed on a lymph node biopsy, similar to TAFRO syndrome. Furthermore, the results of the bone marrow biopsy showed no neoplastic growth of plasma cells, and the serum VEGF levels increased only mildly and did not meet the diagnostic criteria for POEMS syndrome.

In conclusion, we encountered a case of DNTM positive for anti-IFN- $\boldsymbol{\gamma}$ neutralizing antibodies mimicking TAFRO and POEMS syndromes. Since patients with DNTM have various systemic symptoms, it is important to distinguish this condition from systemic autoimmune diseases by a detailed examination. As the combination of antimicrobial chemotherapy with glucocorticoid and intravenous immunoglobulin improved the symptoms in this case, glucocorticoids may be an effective method of suppressing the production of anti-IFN- $\gamma$ antibodies in DNTM. Since the treatment strategy for anti-IFN- $\gamma$ neutralizing antibody-positive DNTM has not yet been clearly defined, the further accumulation of such cases and the establishment of an optimal treatment strategy will be important in future studies.

\section{The authors state that they have no Conflict of Interest (COI).}

\section{Acknowledgement}

We thank all of our colleagues in our department for their helpful cooperation, suggestions, and meaningful discussions regarding this case. We would like to thank Editage (www.Editage. com) for English language editing. This work was supported by JSPS KAKENHI Grant No. JP19K08914 (RY) and SENSHIN Medical Research Foundation (RY).

\section{Patient consent}

Written informed consent for publication was obtained from the patient.

\section{References}

1. Aoki A, Sakagami T, Yoshizawa K, et al. Clinical Significance of Interferon-gamma Neutralizing Autoantibodies Against Disseminated Nontuberculous Mycobacterial Disease. Clin Infect Dis 66: 1239-1245, 2018.

2. Dispenzieri A. POEMS Syndrome: 2019 Update on diagnosis, risk-stratification, and management. American Journal of Hematology 2019.

3. Srkalovic G, Marijanovic I, Srkalovic MB, Fajgenbaum DC. TAFRO syndrome: New subtype of idiopathic multicentric Castleman disease. Bosn J Basic Med Sci 17: 81-84, 2017.

4. Shibata S, Tabata S, Morita H, et al. Borderline Case of TAFRO Syndrome and POEMS Syndrome. Intern Med 60: 1589-1595, 2021.

5. Henkle E, Winthrop KL. Nontuberculous Mycobacteria Infections in Immunosuppressed Hosts. Clinics in Chest Medicine 36: 91-99, 2015.

6. Browne SK, Burbelo PD, Chetchotisakd P, et al. Adult-Onset Immunodeficiency in Thailand and Taiwan. New England Journal of Medicine 367: 725-734, 2012.

7. Ishii T, Tamura A, Matsui H, et al. Disseminated Mycobacterium avium complex infection in a patient carrying autoantibody to interferon- $\gamma$. Journal of Infection and Chemotherapy 19: 1152$1157,2013$.

8. Wu UI, Holland SM. Host susceptibility to non-tuberculous mycobacterial infections. Lancet Infect Dis 15: 968-980, 2015.

9. Browne SK, Zaman R, Sampaio EP, et al. Anti-CD20 (rituximab) therapy for anti-IFN-gamma autoantibody-associated nontuberculous mycobacterial infection. Blood 119: 3933-3939, 2012. 
10. Koya $T$, Tsubata $C$, Kagamu $H$, et al. Anti-interferon-gamma autoantibody in a patient with disseminated Mycobacterium avium complex. J Infect Chemother 15: 118-122, 2009.

11. Baerlecken N, Jacobs R, Stoll M, Schmidt RE, Witte T. Recurrent, multifocal Mycobacterium avium-intercellulare infection in a patient with interferon-gamma autoantibody. Clin Infect Dis 49: e7678, 2009.

12. Furuuchi $K$, Morimoto $K$, Yoshiyama $T$, et al. Interrelational changes in the epidemiology and clinical features of nontuberculous mycobacterial pulmonary disease and tuberculosis in a referral hospital in Japan. Respiratory Medicine 152: 74-80, 2019.

13. Griffith DE, Aksamit T, Brown-Elliott BA, et al. An official ATS/ IDSA statement: diagnosis, treatment, and prevention of nontuberculous mycobacterial diseases. Am J Respir Crit Care Med 175: 367-416, 2007.

14. Keragala BSDP, Gunasekera CN, Yesudian PD, et al. Disseminated Mycobacterium simiae infection in a patient with adult-onset immunodeficiency due to anti-interferon-gamma antibodies - a case report. BMC Infectious Diseases 20: 2020.

15. Sprague J, Leibowitz M, Chiu MW. Cutaneous infection with Mycobacterium kansasii in a patient with myelodysplastic syndrome and Sweet syndrome. Cutis 96: E10-E12, 2015.

16. Franco-Paredes C, Marcos LA, Henao-Martínez AF, et al. Cutaneous Mycobacterial Infections. Clinical Microbiology Reviews 32: 2018.

17. Griffith DE, Brown-Elliott BA, Wallace RJ Jr. Thrice-weekly clarithromycin-containing regimen for treatment of Mycobacterium kansasii lung disease: results of a preliminary study. Clin Infect Dis 37: 1178-1182, 2003.

18. Shitrit D, Baum GL, Priess R, et al. Pulmonary Mycobacterium kansasii infection in Israel, 1999-2004: clinical features, drug susceptibility, and outcome. Chest 129: 771-776, 2006.

19. Masaki Y, Kawabata H, Takai K, et al. Proposed diagnostic criteria, disease severity classification and treatment strategy for TAFRO syndrome, 2015 version. Int J Hematol 103: 686-692, 2016.

20. Fajgenbaum DC, Uldrick TS, Bagg A, et al. International, evidence-based consensus diagnostic criteria for HHV-8-negative/ idiopathic multicentric Castleman disease. Blood 129: 1646-1657, 2017.

21. Oka K, Yamane M, Yokota Y, et al. Disseminated Mycobacterium genavense infection mimicking TAFRO syndrome. J Infect Chemother 26: 1095-1099, 2020.

22. Nei T, Okabe M, Mikami I, et al. A non-HIV case with disseminated Mycobacterium kansasii disease associated with strong neutralizing autoantibody to interferon- $\gamma$. Respir Med Case Rep 8: 10 13, 2013.

23. Ishii $\mathrm{T}$, Tamura A, Matsui $\mathrm{H}$, et al. Disseminated Mycobacterium avium complex infection in a patient carrying autoantibody to interferon- $\gamma$. J Infect Chemother 19: 1152-1157, 2013.
24. Suzuki K, Terada J, Sasaki Y, et al. Pulmonary Mycobacterium fortuitum infection with cervical lymphadenitis in a patient carrying autoantibodies to interferon- $\gamma$. Intern Med 53: 1361-1364, 2014.

25. Hase I, Morimoto K, Sakagami T, Kazumi Y, Ishii Y, van Ingen J. Disseminated Mycobacterium gordonae and Mycobacterium mantenii infection with elevated anti-IFN- $\gamma$ neutralizing autoantibodies. J Infect Chemother 21: 468-472, 2015.

26. Koizumi Y, Sakagami T, Nishiyama N, et al. Rituximab Restores IFN- $\gamma$-STAT1 Function and Ameliorates Disseminated Mycobacterium avium Infection in a Patient with Anti-Interferon- $\gamma$ Autoantibody. J Clin Immunol 37: 644-649, 2017.

27. Tanaka S, Hoshino Y, Sakagami T, Fukano H, Matsui Y, Hiranuma O. Pathogenicity of Mycolicibacterium phlei, a non-pathogenic nontuberculous mycobacterium in an immunocompetent host carrying anti-interferon gamma autoantibodies: a case report. BMC Infect Dis 19: 454, 2019.

28. Namkoong H, Asakura T, Ishii M, et al. First report of hepatobiliary Mycobacterium avium infection developing obstructive jaundice in a patient with neutralizing anti-interferon-gamma autoantibodies. New Microbes New Infect 27: 4-6, 2019.

29. Kashihara E, Fujita K, Uchida N, Yamamoto Y, Mio T, Koyama H. Case Report: Disseminated Mycobacterium kansasii Disease in a Patient with Anti-Interferon-Gamma Antibody. Am J Trop Med Hyg 101: 1066-1069, 2019.

30. Yamaba Y, Takakuwa O, Wang Z, et al. Disseminated Mycobacterium avium Infection Complicated with Chylous Ascites in a Patient with Neutralizing Autoantibodies to Interferon- $\gamma$. Intern Med 59: 3195-3200, 2020.

31. Harada M, Furuhashi K, Karayama M, et al. Subcutaneous injection of interferon gamma therapy could be useful for anti-IFN- $\gamma$ autoantibody associated disseminated nontuberculous mycobacterial infection. J Infect Chemother 27: 373-378, 2021.

32. Mochizuka Y, Kono M, Hirama R, et al. Endobronchial Lesions from Disseminated Mycobacterium avium Infection in a Patient with Anti-interferon-gamma Autoantibodies. Intern Med 2021.

33. Asako M, Matsunaga $H$, Nakahara W, et al. Mycobacterial lymphadenitis without granuloma formation in a patient with antiinterferon-gamma antibodies. Int J Hematol 114: 630-635, 2021.

34. Nagamura N, Imada T. Anti-interferon-gamma autoantibody related disseminated nontuberculous mycobacteriosis with pathological features of immunoglobulin G4-related disease. Immunol Med $1-6,2021$.

The Internal Medicine is an Open Access journal distributed under the Creative Commons Attribution-NonCommercial-NoDerivatives 4.0 International License. To view the details of this license, please visit (https://creativecommons.org/licenses/ by-nc-nd/4.0/).

\section{(C) The Japanese Society of Internal Medicine} Intern Med Advance Publication 